\title{
Synthesis and characterization of some Chromium(III) complexes of dibasic tridentate hydrazone schiff base ligands
}

\author{
P.K.Singh ${ }^{\mathrm{a}}$, Kamalika Banerjee ${ }^{\mathrm{b}}$, Sangeeta Singla ${ }^{\mathrm{c}}$ \\ ${ }^{A}$ Dr. Pramod Kumar Singh, Associate Professor, Department of Chemistry, Kirorimal College, University of \\ Delhi, Delhi-110007, India, \\ ${ }^{b}$ Dr.Kamalika Banerjee, Associate Professor, School of Sciences, Chemistry, IGNOU, Maidan Garhi, Delhi- \\ 110068, India, \\ ${ }^{c}$ Sangeeta Singla, Associate Professor, Department of applied Science and Humanities, Dronacharya College of \\ Engineering, Gurgaon- 122001, Haryana, India
}

\begin{abstract}
Coordination complexes of $\mathrm{Cr}(\mathrm{III})$ with four tridentate Schiff base ligands viz. N-(2-hydroxy-1-naphthaldehyde)$\mathrm{N}^{a}$-(4-nitrobenzoyl)hydrazone(HNNH $\left.=\mathrm{H}_{2} \mathrm{~L}^{1}\right), \quad \mathrm{N}$-(2-hydroxy-4-methoxybenzaldehyde)- $\mathrm{N}^{a}$-(2-furoyl) hydrazone (HMFH $\left.=\mathrm{H}_{2} \mathrm{~L}^{2}\right)$, $\mathrm{N}$-(2-hydroxyacetophenone)- $\mathrm{N}^{3}$-(2-theonyl) hydrazone (HATH $\left.=\mathrm{H}_{2} \mathrm{~L}^{3}\right)$ and $\mathrm{N}$-(2hydroxy-5-methylacetophenone)-N"-(3-toloyl) hydrazone (HMAT $=\mathrm{H}_{2} \mathrm{~L}^{4}$ ) have been synthesized and characterized by elemental analysis, magnetic susceptibility, molar conductance, thermogravimetric analysis and spectral (IR, electronic, NMR) measurements. IR spectra indicates that the ligand behave as dibasic tridentate ligand in a chelate coordinating to $\mathrm{Cr}(\mathrm{III})$ ion through ketonic oxygen, azomethine nitrogen and by both enolic and phenolic protons (except in $\mathrm{H}_{2} \mathrm{~L}^{1}$ by naphtholic oxygen atom) via double deprotonation of ligands. The magnetic and spectral data indicate chelate in octahedral environment and analytical data suggest 1:1 stoichiometries for the complexes.
\end{abstract}

Key words: Complexes, Schiff base, Molar conductance, Analysis, Ligands, Azomethine nitrogen, Octahedral

\section{INTRODUCTION}

Hydrazones are organic compounds characterized by the presence of $-\mathrm{NH}-\mathrm{N}=\mathrm{CH}-$ group in their molecule. The coordination chemistry of aroylhydrazones has received much impetus due to its remarkable anticancer, antimicrobial, antiviral, vasodilator, analgesic and anti inflammatory properties exhibited by these compounds which can be related to their metal complexing abilities [1-9]. This paper presents the synthesis and characterization of four new tridentate Schiff base ligands, N-(2-hydroxy-1naphthaldehyde)- $\mathrm{N}^{x}$-(4-nitrobenzoyl)hydrazone
( $\mathrm{HNNH}$
$=$
$\left.\mathrm{H}_{2} \mathrm{~L}^{1}\right), \mathrm{N}$-(2-hydroxy-4methoxybenzaldehyde)- $\mathrm{N}^{x}$-(2-furoyl) hydrazone (HMFH $\left.=\mathrm{H}_{2} \mathrm{~L}^{2}\right), \mathrm{N}-\left(2\right.$-hydroxyacetophenone) $-\mathrm{N}^{x}$ (2-theonyl) hydrazone (HATH $\left.=\mathrm{H}_{2} \mathrm{~L}^{3}\right)$ and $\mathrm{N}$-(2hydroxy-5-methylacetophenone)- $\mathrm{N}^{x}$-(3-toloyl) hydrazone (HMAT $=\mathrm{H}_{2} \mathrm{~L}^{4}$ ) and studying their coordinating behaviour by coordinating with $\mathrm{Cr}(\mathrm{III})$ ions (Figure 1).

\section{EXPERIMENTS}

All the chemicals and chromium chloride used in the synthesis of the ligands and complexes were of reagent grade and used without purification. The solvents were dried before use by conventional method.

\subsection{Synthesis of the ligands}

All the four ligands were obtained by condensation of ethanolic solution of acid hydrazides with ethanolic solution of hydroxyl aromatic aldehydes and ketones. The structures of the aforementioned ligands were identified by elemental analysis, IR and ${ }^{1} \mathrm{H}$ NMR. The purity of the ligands was checked by TLC. Ligands 2-furoyl hydrazine [10] and 2-hydroxy -5methylacetophenone [11] were prepared by known method.

The ligand $\mathrm{H}_{2} \mathrm{~L}^{1}$ was obtained by condensation reaction of 2-hydroxy-1naphthaldehyde and 4-nitrobenzoylhydrazide in ethanol at 1:1 molar ratio by heating for $4 \mathrm{Hrs}$. under reflux. The precipitate produced was separated by filtration, washed twice with ethanol and dried in vacuum. $\mathrm{H}_{2} \mathrm{~L}^{2}, \mathrm{H}_{2} \mathrm{~L}^{3}$ and $\mathrm{H}_{2} \mathrm{~L}^{4}$ ligands were also obtained by the method similar to that of $\mathrm{H}_{2} \mathrm{~L}^{1}$. 


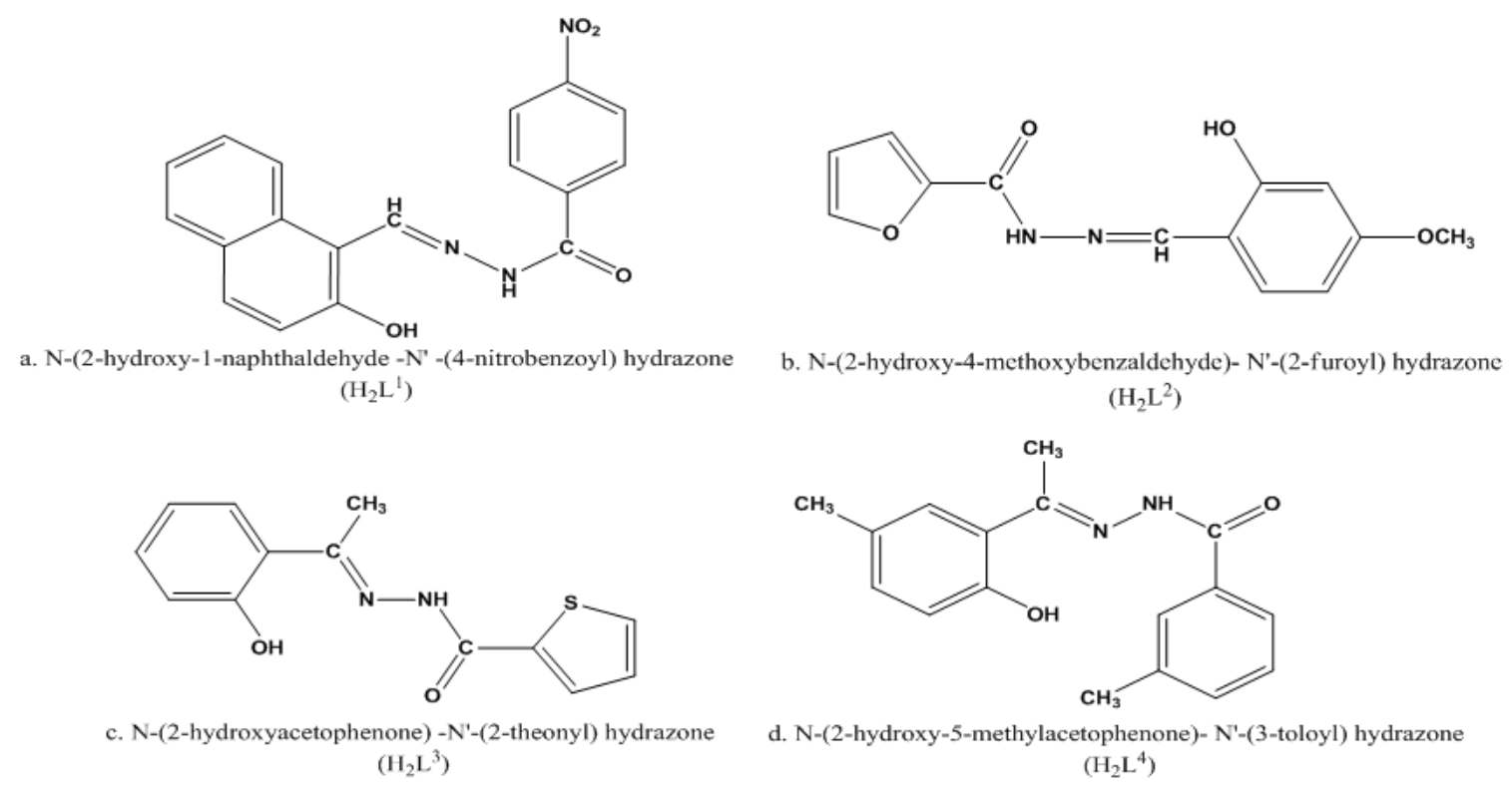

Figure.1: Structure of Ligands

\subsection{Synthesis of complexes}

The alcoholic solution of ligands and chromium chloride were mixed in equimolar amount. The reaction mixture was refluxed on water bath for 3 to 4 hours with stirring. The precipitate of the resulting complex was filtered, washed with ethanol followed by ether. Finally the complexes were dried in vacuum over anhydrous $\mathrm{CaCl}_{2}$ and the purity was checked by TLC and elemental analysis.

\section{ELEMENTAL ANALYSIS AND PHYSICAL MEASUREMENTS}

$\mathrm{C}, \mathrm{H}$ and $\mathrm{N}$ were determined micro analytically and metal contents were estimated using Perkin-Elmer 2380 atomic absorption spectrophotometer. The chloride was analyzed by standard method [12]. IR spectra were recorded on Perkin-Elmer FT-IR spectrophotometer as $\mathrm{KBr}$ discs in the $4000-200 \mathrm{~cm}^{-1}$ region. Electronic spectra were recorded in DMF on Beckman DU-2 spectrophotometer. ${ }^{1} \mathrm{H}$ NMR spectra were recorded on Varian FT-80A NMR spectrophotometer using DMSO- $d_{6}$ as solvent and TMS as internal standard. Magnetic measurements were carried out at room temperature using Gouy's method employing
$\mathrm{Hg}\left[\mathrm{Co}(\mathrm{SCN})_{4}\right]$ for calibration purpose and were corrected for diamagnetism by using Pascal's constants. Molar conductance was measured in $\operatorname{DMF}\left(10^{-3} \mathrm{M}\right)$ with digital conductivity model 304 $\mathrm{X}$-band. EPR spectra were recorded on JEOL JES3XG ESR spectrometer. Thermal behavior was monitored on 8150 thermo analyzer at the heating rate of $10^{\circ} \mathrm{C} / \mathrm{min}$.

\section{RESULTS AND DISCUSSION}

These ligands are all white solids, insoluble in solvents such as ethanol, acetone, chloroform, benzene and carbon tetrachloride, but soluble in strong polar solvents such as DMF and DMSO. All the complexes were air stable and nonhygroscopic. The melting point of the complexes is higher than that of the ligands, revealing that complexes are much more stable than the ligands. The molar conductance of chloride complexes of chromium lies in the range of 81-84 $\Omega^{-1} \mathrm{~cm}^{-2} \mathrm{~mol}^{-1}$ (at $25^{\circ} \mathrm{C}$ ) attributed to $1: 1$ electrolyte ( as mentioned in Table 1) which indicate that the chloride ion is not affected by DMF and still present in the coordination sphere as counter ion to balance the charge only but not in coordination [13] 
Table 1. Elemental Analysis of the ligand and their complexes

\begin{tabular}{|l|l|l|l|l|l|l|l|l|}
\hline \multirow{2}{*}{ Ligands } & & & \multicolumn{5}{|l|}{ Found (Calculated) $\%$} & M \\
\cline { 2 - 9 } & $\begin{array}{l}\text { Decompositon } \\
\text { Temperature } \\
\left({ }^{0} \mathrm{C}\right)\end{array}$ & Color & Yield (\%) & $\mathrm{C}$ & $\mathrm{H}$ & $\mathrm{N}$ & $\begin{array}{l}\text { Molar } \\
\text { conductance } \\
\Omega^{-1} \mathrm{~cm}^{-2} \mathrm{~mol}^{-1}\end{array}$ \\
\hline $\begin{array}{l}{\left[\mathrm{H}_{2} \mathrm{~L}^{1}\right]} \\
\left(\mathrm{C}_{18} \mathrm{H}_{13} \mathrm{O}_{4} \mathrm{~N}_{3}\right)\end{array}$ & $206-208$ & White & 79.20 & $\begin{array}{l}63.80 \\
(64.48)\end{array}$ & $\begin{array}{l}3.20 \\
(3.88)\end{array}$ & $\begin{array}{l}12.10 \\
(12.54)\end{array}$ & - & - \\
\hline $\begin{array}{l}{\left[\mathrm{H}_{2} \mathrm{~L}^{2}\right]} \\
\left(\mathrm{C}_{13} \mathrm{H}_{12} \mathrm{O}_{4} \mathrm{~N}_{2}\right)\end{array}$ & $180-186$ & White & 75.00 & $\begin{array}{l}59.30 \\
(60.00)\end{array}$ & $\begin{array}{l}4.00 \\
(4.62)\end{array}$ & $\begin{array}{l}10.12 \\
(10.77)\end{array}$ & - & - \\
\hline $\begin{array}{l}{\left[\mathrm{H}_{2} \mathrm{~L}^{3}\right]} \\
\left(\mathrm{C}_{13} \mathrm{H}_{12} \mathrm{~N}_{2} \mathrm{O}_{2} \mathrm{~S}\right)\end{array}$ & $182-185$ & White & 82.10 & $\begin{array}{l}58.90 \\
(60.00)\end{array}$ & $\begin{array}{l}4.20 \\
(4.62)\end{array}$ & $\begin{array}{l}10.50 \\
(10.77)\end{array}$ & - & - \\
\hline $\begin{array}{l}{\left[\mathrm{H}_{2} \mathrm{~L}^{4}\right]} \\
\left(\mathrm{C}_{17} \mathrm{H}_{18} \mathrm{~N}_{2} \mathrm{O}_{2}\right)\end{array}$ & $190-194$ & White & 89.60 & $\begin{array}{l}71.97 \\
(72.05)\end{array}$ & $\begin{array}{l}5.80 \\
(6.10)\end{array}$ & $\begin{array}{l}9.67 \\
(9.76)\end{array}$ & - & - \\
\hline$\left[\mathrm{CrL}^{1} \mathrm{Cl}\right] \cdot \mathrm{H}_{2} \mathrm{O}$ & $250-255^{\circ} \mathrm{C}$ & black & 69 & $\begin{array}{l}48.40 \\
(49.26)\end{array}$ & $\begin{array}{l}3.10 \\
(3.96)\end{array}$ & $\begin{array}{l}9.30 \\
(9.57)\end{array}$ & $\begin{array}{l}11.44 \\
(11.85)\end{array}$ & 81.0061 \\
\hline$\left[\mathrm{CrL}^{2} \mathrm{Cl}\right] \cdot \mathrm{H} 2 \mathrm{O}$ & $240-244$ & Rust & 72 & $\begin{array}{l}42.30 \\
(42.92)\end{array}$ & $\begin{array}{l}3.21 \\
(3.30)\end{array}$ & $\begin{array}{l}7.29 \\
(7.70)\end{array}$ & $\begin{array}{l}14.10 \\
(14.30)\end{array}$ & 79.00 \\
\hline$\left[\mathrm{CrL}{ }^{3} \mathrm{Cl}\right] \cdot \mathrm{H}_{2} \mathrm{O}$ & $241-245^{\circ} \mathrm{C}$ & Rust & 73 & $\begin{array}{l}42.29 \\
(42.92)\end{array}$ & $\begin{array}{l}3.10 \\
(3.30)\end{array}$ & $\begin{array}{l}7.24 \\
(7.70)\end{array}$ & $\begin{array}{l}14.14 \\
(14.30)\end{array}$ & 83.24 \\
\hline$\left[\mathrm{CrL}^{4} \mathrm{Cl}\right] \cdot \mathrm{H}_{2} \mathrm{O}$ & $245-251$ & Black & 72 & $\begin{array}{l}52.24 \\
(52.92)\end{array}$ & $\begin{array}{l}4.24 \\
(4.67)\end{array}$ & $\begin{array}{l}6.92 \\
(7.26)\end{array}$ & $\begin{array}{l}13.12 \\
(13.48)\end{array}$ & 84.00 \\
\hline
\end{tabular}

${ }^{a}$ Measured in $10^{-3} \mathrm{M}$ DMF solution at room temperature.

\subsection{Infrared Spectral}

The IR spectra of the ligand and complexes were recorded as $\mathrm{KBr}$ discs in the 4000$400 \mathrm{~cm}^{-1}$ region. The IR spectra of the ligand shows the characteristics absorption band at 3141-3279, $1640-1672,1540-1570,1490-1525$ and $955-970$ $\mathrm{cm}^{-1}$ are attributed to $\mathrm{v}(\mathrm{N}-\mathrm{H}), \mathrm{v}(\mathrm{C}=\mathrm{O}), \mathrm{v}(\mathrm{C}=\mathrm{N})$, $\delta(\mathrm{N}-\mathrm{H})$ and $\mathrm{v}(\mathrm{N}-\mathrm{N})$, respectively. The IR spectra of the complexes reveal significant changes compared to those of the ligands. The absorption bands at $3490-3540 \mathrm{~cm}^{-1}$ for $\mathrm{v}(\mathrm{O}-\mathrm{H})$ in the free ligands disappeared on complexation, indicating coordinated through a deprotonated oxygen. The bands due to $v(\mathrm{~N}-\mathrm{H}), v(\mathrm{~N}-\mathrm{N})$ and $\delta(\mathrm{N}-\mathrm{NH})$ are absent in these complexes suggesting the loss of carbonyl group due to enolization. This is further supported by the appearance of two new bands observed in the region 1590-1620 and 1290-1330 $\mathrm{cm}^{-1}$ attributed to $\mathrm{v}(=\mathrm{C}=\mathrm{N}-\mathrm{N}=\mathrm{C}=)$ and $\mathrm{v}\left(\mathrm{NCO}^{-}\right)$ vibrations respectively [14]. The spectra of the complexes show that furyl ring oxygen and theonyl ring sulphur does not participate in bonding with $\mathrm{Cr}(\mathrm{III})$ ion [15].

The band of $v(\mathrm{C}=\mathrm{N})$ of all the ligands undergoes a bathochromic shift by ca $40-80 \mathrm{~cm}^{-1}$ where as $v(\mathrm{~N}-\mathrm{N})$ band exhibits a hypsochromic shift of ca $35-55 \mathrm{~cm}^{-1}$, which indicate that the $\mathrm{Cr}(\mathrm{III})$ ion form neutral coordination compound with the ligands in the enol form through the azomethine nitrogen and amide oxygen negative ion [15]. A shift of $\mathrm{v}(\mathrm{C}=\mathrm{N})$ band to a lower frequency is due to the conjugation of $p$ orbital on the double bond with $d$ orbital on the $\mathrm{Cr}(\mathrm{III})$ ion with reduction of force constant. A shift of $v(\mathrm{~N}-\mathrm{N})$ band to a higher frequency is attributed to the electron attracting inductive effect when forming the conjugated system [16]. The characteristic band due to naphthyl ring and phenyl ring of the ligands and their chelates remains intact. In the far IR region two new bands ca 425-450 and ca 310-325 $\mathrm{cm}^{-1}$ are observed in the spectrum of $\mathrm{Cr}(\mathrm{III})$ complexes can be attributed to $\mathrm{v}(\mathrm{Cr}-\mathrm{O})$ and $v(\mathrm{Cr}-\mathrm{N})$ bands [17]. The new absorption band ca $3290-3390 \mathrm{~cm}^{-1}$ in all the complexes assigned to the $\mathrm{O}-\mathrm{H}$ stretching vibrations of the crystal water involved in the complexes.

\section{2. ${ }^{1} \mathrm{H}$ NMR Spectra}

The ${ }^{1} \mathrm{H}$ NMR Spectra of the ligands were recorded in DMSO $\left(d_{6}\right)$ using TMS as internal standard. There are two sharp singlets at very downfield region of the spectrum i.e. at $\delta 10.90$ and $\delta 10.10 \mathrm{ppm}$ in all ligands are assigned to $\mathrm{OH}$ and $\mathrm{NH}$ protons respectively. The down field shift of these protons suggest the possibility of considerable extent of hydrogen bonding involved, which decreases the electron density around the 
proton and moves the proton absorption to lower field.

The ${ }^{1} \mathrm{H}$ NMR of the ligand $\mathrm{H}_{2} \mathrm{~L}^{1}$ shows peak of naphthalene ring proton at $\delta 6.20-8.60 \mathrm{ppm}$ (multiplets), $\mathrm{NCH}$ proton at $\delta 8.55 \mathrm{ppm}$ (singlet), nitrobenzoyl proton at $\delta 8.15 \mathrm{ppm}$ (doublet) and $\delta 8.35 \mathrm{ppm}$ (doublet). The lower value of nitrobenzoyl proton at $\delta 8.15 \mathrm{ppm}$ (doublet) compared to $\delta 8.35$ is due to presence of electron withdrawing nitro group at its ortho position.

The ${ }^{1} \mathrm{H}$ NMR of the ligand $\mathrm{H}_{2} \mathrm{~L}^{2}$ shows peak of $\mathrm{NCH}$ proton at $\delta 8.55 \mathrm{ppm}$ (singlet), methoxy proton at $\delta 3.77 \mathrm{ppm}$ (singlet), three peaks of aromatic ring protons in the range of $\delta 6.53-7.47$ ppm and three peaks in the range of $\delta$ 6.67-7.88 ppm due to slight different environment of three furoyl protons

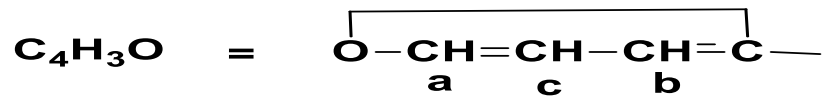

The ${ }^{1} \mathrm{H}$ NMR of the ligand $\mathrm{H}_{2} \mathrm{~L}^{3}$ shows peak at $\delta 2.35 \mathrm{ppm}$ (singlet) for $\mathbf{H}_{\mathbf{3}} \mathbf{C}-\mathbf{C}=\mathbf{N}-$ methyl protons, a complex pattern of peaks in the range $\delta 7.80 \mathrm{ppm}$ for aromatic protons and three peaks in the range of $\delta 6.67-7.75 \mathrm{ppm}$ for the three theonyl protons in different environments.

The ${ }^{1} \mathrm{H}$ NMR of the ligand $\mathrm{H}_{2} \mathrm{~L}^{4}$ also shows peak at $\delta 2.39 \mathrm{ppm}$ (singlet) for $\mathbf{H}_{\mathbf{3}} \mathbf{C}-\mathbf{C}=\mathbf{N}-$ methyl protons, at $\delta 2.20 \mathrm{ppm}$ (singlet) for aromatic methyl proton and a complex pattern was observed in the range $\delta 6.70-7.95 \mathrm{ppm}$ for acetophenone ring protons and totyl protons. The ${ }^{1} \mathrm{H}$ NMR spectra of the complexes cannot be obtained due to interference in their paramagnetic properties.

\subsection{Electronic Spectra and Magnetic studies}

The assignment of various $d-d$ transitions and charge transfer bands in the spectra of the complexes are based on the works of Lever [18] and Drago[19]. The Electronic spectra of all complexes were recorded in DMF at room temperature. The electronic spectra of $\mathrm{Cr}$ (III) complexes exhibits three bands at $18880-19120 \mathrm{~cm}^{-}$ 1 ( $\left.v_{1}\right), 24650-25875 \mathrm{~cm}^{-1}\left(v_{2}\right)$, and 39900-41055 $\mathrm{cm}^{-1}\left(\mathrm{v}_{3}\right)$, corresponding to ${ }^{4} \mathrm{~A}_{2 \mathrm{~g}} \rightarrow{ }^{4} \mathrm{~T}_{2 \mathrm{~g}}(\mathrm{~F})$ and ${ }^{4} \mathrm{~A}_{2 \mathrm{~g}}$ $\rightarrow{ }^{4} \mathrm{~T}_{1 \mathrm{~g}}(\mathrm{~F}) \quad$ and $\quad{ }^{4} \mathrm{~A}_{2 \mathrm{~g}} \rightarrow{ }^{4} \mathrm{~T}_{1 \mathrm{~g}}(\mathrm{P}) \quad$ transitions respectively, characteristics of octahedral geometry around the $\mathrm{Cr}$ (III) ion [20]. The magnetic moment value obtained for $\mathrm{Cr}$ (III) complexes lies in the range of $3.89-3.98 \mathrm{BM}$ which corresponds to octahedral field.

\subsection{Thermal Analysis}

Thermogravimetric experiments of the ligands and the $\mathrm{Cr}$ (III) complexes were carried out in the temperature range $50-750^{\circ} \mathrm{C}$ with heating rate of $10^{\circ} \mathrm{C} / \mathrm{min}$. The thermal analysis of the ligand show two endothermic peaks in DTA curve of the ligand. The first curve appeared in the range of $180-210^{\circ} \mathrm{C}$ which corresponds to melting point of ligands because no weight loss were observed in TG curve, while the second peak were observed in the range of $330-360^{\circ} \mathrm{C}$ where the weight loss on the corresponding curve indicates decomposition of ligands which continues up to $480^{\circ} \mathrm{C}$.

All the complexes of $\mathrm{Cr}$ (III) degraded in three stages as shown by TG curve. The first step in the decomposition sequence at $100-120{ }^{0} \mathrm{C}$ corresponds to loss of physically bound water molecule from the crystal lattice, leading to the formation of anhydrous chelate. The presence of water molecule in the lattice indicated by IR spectra is also confirmed by thermometric analyzer. The second step of decomposition lies in the range of $220-240^{\circ} \mathrm{C}$ corresponds to weight loss of Nitrogen. The third step of decomposition starts from $290^{\circ} \mathrm{C}$ and continuous up to $480^{\circ} \mathrm{Cas}$ indicated by the horizontal plateau on the TG curve of all complexes and this decomposed fragments could not be approximated owing to continuous weight loss, indicates the decomposition of organic part of the chelate. The final weight loss of the residue in the temperature range $550-700^{\circ} \mathrm{C}$, as shown by horizontal plateau on the TG curve corresponding $\mathrm{Cr}_{2} \mathrm{O}_{3}$ as the end product [21].

The decomposition temperature of the complexes higher than the ligands, indicate that the thermal stability of the complexes are increased due to the ligand coordinating with the Cr(III) ion to form stable ring.

Based on above data the proposed structures of the complexes are shown in Figure 2. 


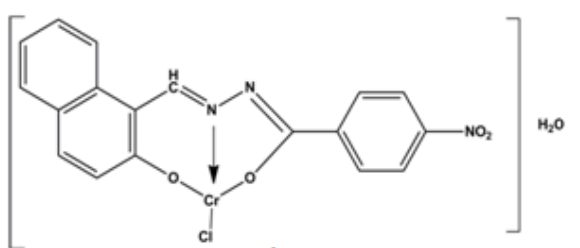

a. $\left[\mathrm{CrL}^{1} \mathrm{Cl}\right] \cdot \mathrm{H}_{2} \mathrm{O}$

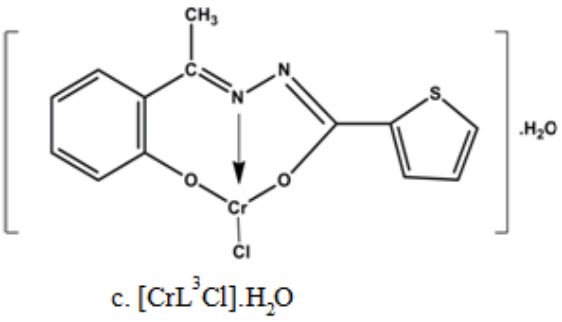<smiles>Cc1ccc2cc(-c3ccco3)[nH][pH]oc2c1</smiles>

b. $\left[\mathrm{CrL}^{2} \mathrm{Cl}\right] \cdot \mathrm{H}_{2} \mathrm{O}$

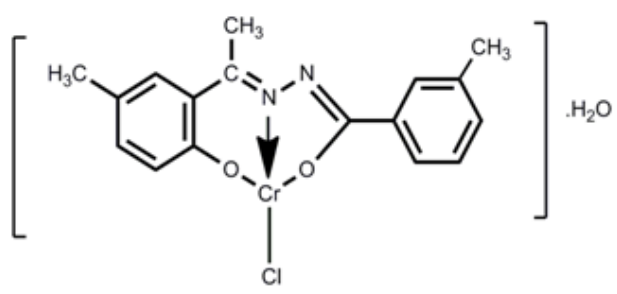

d. $\left[\mathrm{CrL}^{4} \mathrm{Cl}\right] \cdot \mathrm{H}_{2} \mathrm{O}$

Figure 2. Proposed structure of $\mathrm{Cr}$ (III) complexes.

\section{ACKNOWLEDGEMENTS}

The authors are very much thankful to Prof. Ashok K. Prasad from Department of Chemistry, Delhi University for providing all laboratories and research facilities.

\section{REFERENCES}

[1] I.G. Ribeiro,K.C.M. da Silva, S.C. Parrini, A.L.P. de Miranda, C.A.M. Fraga, E.J. Barreiro, Eur. J. Med. Chem., 33, 1998, pp. 225-255.

[2] D.R. Richardson, P.V. Bernhardt, J. Biol. Inorg. Chem., 4, 1999, pp. 226-273.

[3] S. G. Kuçukguzel, S. Rollas, I. Kuçukguzel, M. Kiraz, Eur. J. Med. Chem., 34, 1999, pp. 1093-1100.

[4] U. O. Ozmen, G. Olgun, Spectrochim. Acta A 70, 2008, 641-645.

[5] P. G. Avaji, CH. V. Kumar, S. A. Patil, K. N. Shivananda, C. Nagarajun, Eur. J. Med. Chem., 44, 2009, 3552-3559.

[6] L. M. Lima, F. S. Frattani, J. L. dos Santos, H. C. Castro, C. A. M. Fraga, R. B. Zingali, Eur. J. Med. Chem., 43, 2008, 348356.

[7] G. Visbal, E. Marchán, A. Maldonado, Z. Simoni, M. Navarro, J. Inorg. Biochem., 102, 2008, 547-554.

[8] C. Roullier, C. K. Marylene, W. Pierr Van De, L. L. D. Francoise, B. Joel, Bioorg. Med. Chem. Lett., 20, 2010, 4582-4586.

[9] J. K. Amartey, I. Al-Jammaz, B. Al-Otaibi, B. Esguerra, Nucl. Med. Bio., 29, 2002, 817-823.
[10] Singh B., and Srivastava P., Transition Metal Chem., 11, 1986, 106.

[11] Thorn G.D., and Ludwig R.A., "TheDithiocarbamate and related Compounds." New York, 1962.

[12] A.I.Vogel,"A text book of Quantitative Inorganic Chemistry "3rd Ed., ELBS London, 1961.

[13] Singh P.K., Banerjee K., Singla S., IJETMAS, Vol.3, 7, 2015.

[14] Singh P. K., Kumar D. N., Spectrochimica Acta Part A 64, 2006,pp. 853-858.

[15] K. Nakanishi, Infra Red Absorption Spectroscopy, Holden Day, Inc., San Francisco. and Nankodo Co. Ltd. , Tokyo 1962, P.P. 213.

[16] B. S. Garg, P. K. Singh, J. Sharma, Synth. React. Inorg. Met. Org. Chem., 30, 2000, 803-813.

[17] Ohkaku N., and Nakamoto K.,'Metal isotope effect on metal-ligand vibrations. VI. Metal complexes of 8-hydroxyquinoline." Inorg. Chem., 1971, 10,798

[18] A.B.P. Lever, Inorganic electronic spectroscopy, Elsevier, London, 1968.

[19] R.S.Drago, Physical methods in Inorganic Chemistry, Reinhold, London, 1965.

[20] R.S. Drago, D.W. Meek, M.S.Joosten, and L. Laroche, Inorg.Chem., 2, 124, 1963.

[21] Wendlandt W. W., "Thermal Method of Analysis.” Interscience, NewYork, 1964. 